By PERCY E. CLAPP

\title{
A Technical Research Laboratory for the Library
}

Percy E. Clapp is on the staff of the Reference Department of the New York Public Library.

$\mathrm{T}$ HE SIXTH edition of Industrial Research Laboratories of the United States, published by the National Research Council, lists I 769 laboratories. These range from those of the great corporations, Du Pont, Eastman Kodak, and the Bell Telephone Laboratories with a staff of over 2000, to those of small firms with a staff of one or two. They include also the laboratories maintained collectively by industrial associations like the Institute of Paper Chemistry at Lawrence College. The Bureau of Standards, in its latest directory, lists 244 commercial testing laboratories.

The several states maintain 59 agricultural experiment stations and the United States, 8 regional agricultural laboratories, with recent provision for 4 additional regional research laboratories. In the forest service alone there are 12 forest and range experiment stations in addition to the Forest Products laboratory at the University of Wisconsin. The Department of Agriculture estimates that the allotment for industrial research in the United States for 1937 was $\$ 250,000,000$. The appropriation for agricultural research for the year ending June 30, I937 was over $\$ 35,000,000$. This was slightly over one cent per dollar of income from these sources.
The same directory of the Bureau of Standards lists 200 university research laboratories. In them, in the laboratories of the great foundations, in the Bureau of Standards and other governmental laboratories, in the industrial, commercial and private laboratories is conducted the great body of American research.

\section{Research Done in Field of Fine Arts}

Research has also extended to cultural organizations. At the Fogg Art Museum, Harvard, and at several other art museums, technical research has in recent years been undertaken in the field of fine arts. In 1930 Charles C. Williamson both asked and answered the question:

What about research in the library field? A little sporadic work here and there by individuals that may possibly be classified as research. No organized or co-operative plans, or only the beginnings of such in two or three university library schools. No money appropriated anywhere, so far as I know, specifically for research in library service. Not a single person employed anywhere by a library or a library system to study problems of library service. No research fellowships. No research professorships.

An even decade has elapsed since the date of this sweeping indictment, and perhaps Dr. Williamson has understated the case for the library. Without entering the more strictly professional side of library service, there have been in recent 
years most creditable studies along technical lines. Among them are the study of deterioration of paper initiated by Harry Miller Lydenberg, and the studies of microfilm in which Keyes D. Metcalf has long been active. The study of foxing of paper made by Thomas M. Iiams is notable. The measurement of 350,000 books by Henry B. Van Hoesen is basic. The work of the Joint Committee of the American Library Association and Library Binding Institute, and of the A.L.A. Committee on Library Equipment and Appliances is of genuine service. A survey like that made by Robert C. Binkley and outlined in his manual on Methods of Reproducing Research Materials is of great value in integrating and making available the practical results of research. Many libraries have conducted studies with valuable results which are unpublished, and therefore of limited usefulness. However, there is much in Dr. Williamson's statement that will still hold today.

\section{Some Library Problems}

That these studies have not solved all immediate problems is indicated by such recent articles as "Inventions and Books" by Ethel M. Fair in the Library Journal, "Tomorrow" by Dr. Lydenberg in the Library Quarterly, and the "Possibility of Discarding the Card Catalog" by Fremont Rider in the same publication. Paper is the basic stuff of books, and libraries use it in quantity. How much is made in accordance with specifications as thorough as the minimum specifications for class "A" library binding, and how often is it tested for compliance with them? Like questions may be asked about other components of books, the ink and adhesives. There are the conditions vitally affecting library buildings and their occupants, the lighting, the sound, the ventilation. Printing processes begin to shift from graphic to photographic. Photographic records displace descriptive records. Color becomes frequent, and the motion picture records action as well. Records of music and of speech itself begin to supplement the score and printed symbols of language.

All of these changes bring new problems with increasing need of modern laboratory facilities and of present day methods of technical research to solve them.

In any approach to the consideration and introduction of organized technical research in the library, there are a number of points which have important bearings:

Many problems are continuing problems. New problems arise as rapidly as older ones are solved.

While the results of much completed research may be used by libraries, there are plenty of problems peculiar to the library.

The Bureau of Standards can do much, but it cannot conduct the whole research of the nation. The library, like industry, needs to conduct its own research.

The library building is usually not equipped for research, and the library staff is not organized to devote enough time to it. A research laboratory and information service or clearing house might best be maintained at a university with access to its physical, chemical and psychological laboratories.

\section{Regional Laboratory Might Be Practical}

Each library has problems of its own, but most problems affect large groups of libraries and can best be solved collectively. A regional type of laboratory would be easily accessible to a compact 
group of large libraries. Such a regional laboratory, serving a compact group of libraries, could well initiate organized library technical research, and later provide a basis for a comprehensive national organization.

To bring this important subject under consideration, it is proposed that a compact group of about thirty university and public libraries on the eastern seaboard establish a library technical research service and laboratory. This would preferably be situated at some centrally located university where scientific departments would be available without duplication. This service would conduct for its contributing libraries the established tests for paper and other library materials. It would make studies of and conduct experiments with paper, inks, adhesives, binding materials, library conditions, light, sound, air and ventilation, wall coloring and surfaces, floors, various forms of equipment, the physical form of the cata$\log$ as well as other technical problems of libraries.

The research and information service might begin with a staff of one person in charge and one technician. They would require an office, and a laboratory for testing equipment. With little delay a chemist should be added to the staff.

\section{Proposed Support}

It is proposed that the laboratory be supported cooperatively so far as possible by the group of participating libraries, and that the cost be distributed equitably among them, perhaps in proportion to their total library expenditures. Service to other nearby libraries might be given for a small annual fee. It is believed that operation could begin on a budget of about $\$ 7500$. At the beginning, however, it would be advisable to encourage the frequent use of the laboratory as an educational policy rather than to restrict its use in the interest of small economies. While the laboratory should fit into the framework of the institution at which it is located, the selection of subjects of research might be made by a representative committee of the supporting organizations.

This research and information service might make a survey of the results of library research both unpublished and published. It might become a clearing house for unsolved library technical problems. It might integrate and coordinate the library technical research conducted independently with that conducted in the laboratory itself. It should make the results of its study available by publication or otherwise to its contributors and others. It should cooperate with the Joint Committee of the A.L.A. and Library Binding Institute, and with the A.L.A. Committee on Library Equipment and Appliances.

Such a laboratory and information service should, in due course of time, develop a body of knowledge as useful as that produced by industrial and other research laboratories. It should become a training class for library research workers. It should pay, or more than pay for its cost, tend to place technical matters generally upon the sound basis of fact, and result in a better library service. 